\title{
Recognition and Intent-to-Participate of Rural Migrants on Urban and Rural Exchange Business in Namhae County, South Korea
}

\author{
Myeong Sik Park ${ }^{1}$, Inhea Kim², Keun Young Huh ${ }^{3 *}$, and Hai Dang Bui ${ }^{4}$ \\ ${ }^{1}$ Ph.D. Candidate in Urban System Engineering, Gyeongsang National University, Jinju 52828, Korea \\ ${ }^{2}$ Lecturer, Dept. of Horticulture, Gyeongsang National University, Jinju 52828, Korea \\ ${ }^{3}$ Professor, Dept. of Landscape Architecture, Gyeongsang National University, Jinju 52828, Korea \\ ${ }^{4}$ Professor, University of Social Science and Humanities, Vietnam National University of Ho Chi Minh City, Vietnam
}

\section{ABSTRACT}

Background and objective: Rural migrants are an important human resource in urban and rural exchange (URE) business, therefore it is necessary to enhance their awareness and intent-to-participate. This study was to analyze the rural migrants' recognition and intent-to-participate of URE business and to propose the enhancement of them both.

Methods: The questionnaire was designed to analyze the socio-demographic background, motivations, satisfaction with settlement, intent-to-persist, and intent-to-participate of URE business including tourism. The data of 144 respondents was subject to the statistical analysis.

Results: The motives of migration were to enjoy leisure life after retirement, increased tiredness of city life, health problems, etc. The satisfaction with settlement was 3.67 at 5-point Likert scale. The intent-to-recommend and intent-to-publicize were 3.40 and 3.46 , respectively. The intent-to-participate was 3.45 , which was affected by the necessity of URE business and the support of central/local governments, and also showed a significant correlation with the satisfaction with settlement, intent-to-recommend, intent-to-publicize, tourism resources for green tourism or rural tourism, driving a car in Namhae county, and the service and price of meals. They thought the missions that the Namhae county office must focus on were to establish an internal/external public relations systems, establish a support system of central/local governments, and foster/support local leaders.

Conclusion: It is necessary to improve the satisfaction with settlement and intent-to-persist, expand exchanges with local people, improve internal/external public relations systems, foster/support leaders, improve transportation in the county, enhance the service and price of meals, and develop/operate URE programs including tourism.

Keywords: green tourism, intent-to-persist, rural tourism, satisfaction with settlement

\section{Introduction}

Urban and rural exchange (URE) is an interaction and exchange of people, products, culture, and services between cities and rural areas, and tends to emphasize continuous interactions and close relationships (Jang, 2013). According to Article 2 (Definitions) of the Promotion of Mutual Exchange between Cities and Agricultural or Fishing Villages Act established in 2007 in Korea, the term "mutual exchanges between cities and rural communities" is defined as human exchanges between cities and rural communities and the exchange, trade, and provision of commodities, such as agricultural, fishery, or forestry products, services for experience and recreation, information, or culture through a community experiential and recreational business in agricultural and fishing villages or tourist farm business. The term "community experiential and recreational business in an agricultural or fishing village" means a business

This work was supported by Gyeongsang National University Grant in 2020 2021

Received: March 2, 2021, Revised: March 30, 2021, Accepted: April 16, 2021

First author: Myeong Sik Park, smfsgo@naver.com, (10) https://orcid.org/0000-0001-7545-5606

*Corresponding author: Keun Young Huh, sumoto@gnu.ac.kr, (D) https://orcid.org/0000-0002-3105-8745 
run by a community council or a fishing village fraternity to provide city dwellers with experiential and recreational programs and spaces and sell local agricultural, fishery, or forestry products or provide them with lodgings, food, or other services by utilizing the natural environment, traditional culture, or natural resources of the community. This suggests that URE includes community-based green tourism or rural tourism. Here rural tourism includes various experiential elements such as nature, farming, and rural culture (Yu et al., 2013). The purpose of URE is aimed at revitalizing rural areas and a large portion of it is linked to tourism, which provides recreation and leisure. Han (2005) stated that the type of URE most preferred by urban residents is the exchange of recreation and leisure, rather than exchange of materials or human resources. Chancellor et al. (2011) mentioned that tourism has increasingly become a preferred option for rural economic development and that the purpose of tourism is to improve community viability and residents' quality of life.

In order to revitalize URE, it is necessary to enhance the awareness of urban and rural residents, nurture competent leaders in rural areas who can manage URE business, and build a partnership. Given that most rural societies in current times comprise an intricate mix of long-term residents, seasonal-home owners and migrants, and each with their distinct set of life stories and value preferences with regard to their place of dwelling (Saxena, 2014), they need to be understood separately. Amidst the aging in population and the decrease in number of farm households in rural areas of the domestic, the number of rural migrants is increasing every year due to the retirement of baby boomers in line with the economic crisis during the late 2000s, the urban residents' aspiration of rural life, and the government's policies supporting rural migration (Ma et al., 2015). Rural migrants can be a major human resource for URE business. Jang (2013) mentioned it was desirable that recent studies in terms of policies were conducted in accordance with the concept of URE in a broad sense including green tourism and rural tourism, but pointed out that the scopes were mostly nationwide, which means that studies on regional units where UREs were actually taking place had not been conducted. Thus, this study suggests ways to enhance rural migrants' recognition and intent-to-participate of URE business, focusing on Namhae county, South Korea.

\section{Research Methods}

\section{Site and subjects}

The site is Namhae county (Namhae-gun) in South Gyeongsang province (Gyeongsangnam-do) known to be rich in natural and cultural resources (Kweon and Lee, 2016). The Namhae county office is currently operating a rural migration support center and implementing various URE projects. Namhae county is located in a set of islands in the south coast of Korea and is connected to the mainland via the Namhaedaegyo bridge. The area of the county is $357.62 \mathrm{~km}^{2}$, with a population of approximately 43,000 as of December 2020. Since the public-selected local autonomy was implemented in 1995, it has continuously realized the value of green growth and promotes 'ecological and cultural tourism' that utilizes the well-preserved natural environment and the local culture of Namhae county as a project that can revitalize the local economy (Kim, 2010). This can be a part of URE, which places importance on the participation of local residents and features the exchanges between city and local residents with their participation in cultural events. Recently, various efforts are being made to preserve ecological and cultural landscape resources. The subjects of this study are rural migrants in Namhae county. In general, rural migrants have both urban and rural characteristics as well as economic power, high level of education, various experiences and abilities. They empirically understand the needs of urban residents for recreation and have the intent to provide recreation in rural areas. In other words, they may have the characteristics of both the consumer and supplier of recreation. Thus, it is necessary to analyze the recognition and attitudes of rural migrants as major human resources for URE business by separating them from long-term residents (Saxena, 2014).

\section{Questionnaire design}

As shown in Table 1, the questionnaire was designed to analyze the socio-demographic background of rural mi- 
Table 1. Scheme of questionnaire design to rural migrants on Urban-Rural Exchange (URE) Business in Namhae county, South Korea

\begin{tabular}{|c|c|c|c|}
\hline & Category & No. of questions & Reference \\
\hline $\begin{array}{l}\text { Socio-demographic } \\
\text { background }\end{array}$ & $\begin{array}{l}\text { Gender, age, income, education, previous occupation, } \\
\text { previous residential district, born and raised in }\end{array}$ & 7 & $\begin{array}{l}\text { Lee et al., 2019; } \\
\text { Ma et al., } 2015\end{array}$ \\
\hline $\begin{array}{l}\text { Motives and behaviors } \\
\text { to migrate to rural areas }\end{array}$ & $\begin{array}{l}\text { Motives, type of return, reason for choosing Namhae county, } \\
\text { current residence }\end{array}$ & 4 & $\begin{array}{l}\text { Han, 2005; } \\
\text { Lee et al., } 2019\end{array}$ \\
\hline \multirow[b]{2}{*}{$\begin{array}{l}\text { Satisfaction with settlement } \\
\text { and intent-to-persist }\end{array}$} & Satisfaction, reason for satisfaction or dissatisfaction & \multirow[b]{2}{*}{18} & Choi et al., 2014; \\
\hline & $\begin{array}{l}\text { Intent to move to another rural area, intent to go back to the } \\
\text { city, intent to recommend, intent to publicize }\end{array}$ & & $\begin{array}{l}\text { Han, 2005; } \\
\text { Lee et al., 2004; } \\
\text { Whang, } 2006\end{array}$ \\
\hline \multirow{4}{*}{$\begin{array}{c}\text { Recognition and } \\
\text { intent-to-participate } \\
\text { of URE business including } \\
\text { local tourism }\end{array}$} & Major attractive destinations and images of Namhae county & \multirow{4}{*}{50} & \multirow{4}{*}{$\begin{array}{l}\text { Han, 2005; } \\
\text { Kweon and Lee, 2016; } \\
\text { Lee et al., 2004; } \\
\text { Lee et al., 2019; } \\
\text { Yu et al., } 2013\end{array}$} \\
\hline & $\begin{array}{l}\text { Assessment of tourism resources, accessibility, facilities, } \\
\text { sanitation and cleanliness, public relation and information, } \\
\text { hospitality, service and price, and URE programs }\end{array}$ & & \\
\hline & $\begin{array}{l}\text { Intent-to-participate, awareness, necessity, assessment of the } \\
\text { support of government and local government }\end{array}$ & & \\
\hline & $\begin{array}{l}\text { Information sources, experience of participation, importance- } \\
\text { performance, missions of the Namhae county office }\end{array}$ & & \\
\hline
\end{tabular}

grants, motives and behaviors of migration, satisfaction with settlement and intent-to-persist, and recognition and intent-to-participate in URE business including local tourism (Choi et al., 2014; Han, 2005; Lee et al., 2004; Lee et al., 2019; Kweon and Lee, 2016; Ma et al., 2015; Whang, 2006; Yu et al., 2013). The socio-demographic background included 7 items on gender, age, income, education, previous occupation, previous residential district, and born and raised in. The motives and behaviors of migration included 4 items on motives, types, reasons for choosing Namhae county, and current residence. These items were designed on a nominal scale. The satisfaction with settlement and intent-to-persist included 18 items on satisfaction, reasons for satisfaction or dissatisfaction, intent to move to another rural area or go back to the city, and intent to recommend and publicize the migration to Namhae county. The recognition of local tourism included 2 items on major attractive destinations recommended by rural migrants and the image rural migrants have about Namhae county, and 22 items on the assessment of tourism resources, accessibility, facilities, sanitation/cleanliness, public relations/information, hospitality, and service/price. The recognition and intentto-participate of URE business included 10 items on the assessment of major URE programs, 4 items on intent-to-participate, awareness, necessity and assessment of the support from the central/local government, and 12 items on information sources, experience of participation, importance, and performance and missions of Namhae county office. The scale of the items on satisfaction, intention and evaluation was set to a 5 -point Likert scale $(1=$ strongly disagree to $5=$ strongly agree), and the scale of the rest were set to a nominal scale. Items on major attractive destinations recommended by rural migrants and the image rural migrants have about Namhae county were open-ended questions, with the former listed up to nine and the latter up to three.

\section{Survey and analysis}

The questionnaire-based survey was conducted from October 2019 to January 2020 in the form of a self-report questionnaire. 144 copies excluding those with inadequate responses were used in the analysis. The collected data was analyzed using the IBM SPSS Statistics 24 . Frequency analysis was conducted on variables related to socio-demographic background and the motives and behaviors to mi- 
Table 2. Reliability and item-total statistics of 4 items related to intent-to-persist of the settlement in Namhae county

\begin{tabular}{|c|c|c|c|c|c|}
\hline Item & $\begin{array}{l}\text { Scale mean } \\
\text { if item deleted }\end{array}$ & $\begin{array}{l}\text { Scale variance } \\
\text { if item deleted }\end{array}$ & $\begin{array}{l}\text { Corrected item-total } \\
\text { correlation }\end{array}$ & $\begin{array}{l}\text { Cronbach's Alpha } \\
\text { if item deleted }\end{array}$ & $\begin{array}{c}\text { Cronbach's Alpha } \\
(\text { Number of items }=4)\end{array}$ \\
\hline $\begin{array}{l}\text { Intent to move to another } \\
\text { rural area }\end{array}$ & 9.85 & 6.291 & .671 & .827 & \multirow{4}{*}{.854} \\
\hline Intent to go back to the city & 9.97 & 6.223 & .694 & .816 & \\
\hline Intent to recommend & 9.59 & 6.915 & .699 & .815 & \\
\hline Intent to publicize & 9.52 & 6.684 & .733 & .800 & \\
\hline
\end{tabular}

grate to rural areas in order to understand the characteristics of rural migrants. Descriptive analysis was first conducted on variables related to satisfaction with settlement and intent-to-persist, after which correlation analysis was conducted on all the variables focused on satisfaction with settlement and intent-to-persist. Here, the intent-to-persist is a variable obtained by transforming four variables shown in Table 1 and 2 into a single variable: the values of two variables, the intent to move to another rural area and the intent to go back to the city, were transformed as in Equation 1 to be positive consistent with intent-to-persist in settlement; the Cronbach's Alpha was .854 in the reliability analysis on the two transformed variables and the two other variables; as shown in Table 2, this was higher than the values when certain variables were excluded; in the factor analysis for dimension reduction, the four variables were transformed into a new variable through regression analysis.

$$
\mathrm{Y}=1+(5-\mathrm{X})
$$

[Equation 1]

$\mathrm{Y}:$ intent-to-persist in settlement

$\mathrm{X}$ : intent to move to another rural area or intent to go back to the city

In the assessment of tourism resources, frequency analysis was conducted on two variables of major attractive destinations recommended by rural migrants and the images rural migrants had about Namhae county after classifying destinations or images selected more than two times according to their characteristics, and the others were descriptive analyzed. Descriptive analysis and correlation analysis were conducted on variables related to recognition and intent-to-participate of URE business. To determine the vari- ables that have correlation with intent-to-participate, correlation analysis was conducted on variables related to it, such as satisfaction with settlement, intent-to-persist, and tourism assessment. Frequency analysis was conducted on information source and experience of participation, IPA analysis on the anticipated effects (importance) and performance of URE business (Kim and Huh, 2019; Martilla and James, 1977). To assess the importance and priorities of missions on which Namhae county office must concentrate, post-hoc analysis of one-way ANOVA was conducted using Tukey's range test with $95 \%$ of confidence.

\section{Results and Discussion}

\section{Socio-demograpic background, motives and behaviors}

By gender, $46.9 \%$ of the respondents were men and $53.1 \%$ were women (Table 3). $31.9 \%$ were in their $40 \mathrm{~s}$ and $31.3 \%$ were in their $50 \mathrm{~s}$, showing that most were in their 40s-50s. This was similar to the age groups that visited local festivals (Kim and Jeong, 2006; Lee et al., 2019). Most of the respondents had an income of 2-3 million or 1-2 million KRW (both 32.6\%), followed by 3-4 million KRW (13.9\%). 60.4\% were university graduates, and 9\% completed graduate education. For previous occupation, most of them were self-employed at $31.9 \%$, and $16.3 \%$ were professionals and $10.6 \%$ were office workers. The previous residential district of most respondents was Gyeongsang province (63.0\%), followed by Seoul and Gyeonggi province (27.5\%). 58.5\% were born and raised in urban areas, followed by $22.5 \%$ born and raised in rural 
Table 3. Socio-demographic background of rural migrants responded

\begin{tabular}{|c|c|c|c|}
\hline & Variable & Frequency & Percent (\%) \\
\hline \multirow{3}{*}{ Gender } & Male & 67 & 46.9 \\
\hline & Female & 76 & 53.1 \\
\hline & Total & 143 & 100.0 \\
\hline \multirow{6}{*}{ Age } & $20 \mathrm{~s}$ & 3 & 2.1 \\
\hline & $30 \mathrm{~s}$ & 15 & 10.4 \\
\hline & $40 \mathrm{~s}$ & 46 & 31.9 \\
\hline & $50 \mathrm{~s}$ & 45 & 31.3 \\
\hline & More than 60 & 35 & 24.3 \\
\hline & Total & 144 & 100.0 \\
\hline \multirow{7}{*}{$\begin{array}{l}\text { Income } \\
(\mathrm{KRW})\end{array}$} & $0 \sim 1$ million & 15 & 10.4 \\
\hline & $1 \sim 2$ million & 47 & 32.6 \\
\hline & $2 \sim 3$ million & 47 & 32.6 \\
\hline & $3 \sim 4$ million & 20 & 13.9 \\
\hline & $4 \sim 5$ million & 8 & 5.6 \\
\hline & More than 5 million & 7 & 4.9 \\
\hline & Total & 144 & 100.0 \\
\hline \multirow{6}{*}{ Education } & Elementary school & 1 & 0.7 \\
\hline & Middle school & 6 & 4.2 \\
\hline & High school & 37 & 25.7 \\
\hline & University & 87 & 60.4 \\
\hline & Graduate school & 13 & 9.0 \\
\hline & Total & 144 & 100.0 \\
\hline \multirow{10}{*}{$\begin{array}{l}\text { Previous } \\
\text { occupation }\end{array}$} & Student & 2 & 1.4 \\
\hline & Office worker & 15 & 10.6 \\
\hline & Production worker & 27 & 19.1 \\
\hline & Self-employed & 45 & 31.9 \\
\hline & Public official & 6 & 4.3 \\
\hline & Professional & 23 & 16.3 \\
\hline & Housewife & 17 & 12.1 \\
\hline & Farmer & 2 & 1.4 \\
\hline & Others & 4 & 2.8 \\
\hline & Total & 141 & 100.0 \\
\hline \multirow{5}{*}{$\begin{array}{l}\text { Previous } \\
\text { residential } \\
\text { district }\end{array}$} & $\begin{array}{l}\text { Seoul and Gyeonggi } \\
\text { province }\end{array}$ & 38 & 27.5 \\
\hline & Gyeongsang province & 87 & 63.0 \\
\hline & Jeolla province & 4 & 2.9 \\
\hline & Chungcheong province & 9 & 6.5 \\
\hline & Total & 138 & 100.0 \\
\hline \multirow{5}{*}{$\begin{array}{l}\text { Born and } \\
\text { raised in }\end{array}$} & Rural area & 32 & 22.5 \\
\hline & Fishing Village & 13 & 9.2 \\
\hline & Mountain village & 14 & 9.9 \\
\hline & City & 83 & 58.5 \\
\hline & Total & 142 & 100.0 \\
\hline
\end{tabular}

Note. Missing values within each variable were excluded for frequency analysis. areas. As for motives to migrate to rural areas, the share of leisure life after retirement was the highest at $30.5 \%$, followed by tired of city life $(22.1 \%)$ and health reasons (19.1\%) (Table 4). For the type of migration, conjugal migrations was the highest at $31.2 \%$, followed by family migrations $(27.7 \%)$ and household head first and then family (21.3\%). As a result, most were conjugal or family migrations $(80.2 \%)$. The reason for choosing Namhae county was because of the natural environment (34.4\%), because they like the sea $(21.1 \%)$, and because of acquaintances (15.6\%). This indicates that natural environment and interpersonal relationships are important factors for choosing a rural area to migrate to. For the current residence in Namhae county, most were living in Namhae town (23.6\%), followed by Sangju-myeon township (16.7\%) and Samdong-myeon township (14.6\%). This shows that most rural migrants live in the central area of Namhae county or in the areas with excellent landscape. The characteristics of rural migrants in Namhae county were similar to or the same as the results by Ma et al. (2015). However, the distinctive features were that there were relatively many rural migrants born and raised in urban areas, and that they chose Namhae county because of the healthy and beautiful natural environment rather than financial reasons.

\section{Satisfaction with settlement and intent-to-persist}

Satisfaction with settlement was 3.67, which was close to being satisfied (Table 5). Regarding the reasons for satisfaction, beautiful natural environment and healthy natural environment were at 3.99 and 3.94 respectively, which was close to approve, while the others were close to neutral or below neutral. In particular, low living costs and various income sources were low at 2.58 and 2.52 , respectively. Similarly, Choi et al. (2014) revealed that the satisfaction with settlement of rural migrants nationwide slightly exceeds neutral at 3.24, the satisfaction with natural environment was the highest at 3.83 , and the satisfaction with convenience of living facilities was the lowest at 2.61. Regarding the reason for dissatisfaction, poor income sources and medical facilities / services were relatively high at 3.32 and 3.30 respectively, administrative services and 
Table 4. Motives and behavior of migration to Namhae county

\begin{tabular}{|c|c|c|c|}
\hline \multicolumn{2}{|r|}{ Variable } & Frequency & Percent $(\%)$ \\
\hline \multirow{7}{*}{ Motives of migration } & Tired of city life & 29 & 22.1 \\
\hline & Leisure life after retirement & 40 & 30.5 \\
\hline & Health reasons & 25 & 19.1 \\
\hline & New jobs & 12 & 9.2 \\
\hline & Business linked to agriculture or fishery & 12 & 9.2 \\
\hline & Business linked to tourism & 13 & 9.9 \\
\hline & Total & 131 & 100.0 \\
\hline \multirow{7}{*}{ Type of migration } & Family migration & 39 & 27.7 \\
\hline & Household head first and then family & 30 & 21.3 \\
\hline & Migrating alone & 12 & 8.5 \\
\hline & Migrating with acquaintances & 7 & 5.0 \\
\hline & Conjugal migration & 44 & 31.2 \\
\hline & Others & 9 & 6.4 \\
\hline & Total & 141 & 100.0 \\
\hline \multirow{9}{*}{ Reason for choosing Namhae county } & Homecoming & 19 & 14.8 \\
\hline & Acquaintances & 20 & 15.6 \\
\hline & The sea is good. & 27 & 21.1 \\
\hline & Natural environment & 44 & 34.4 \\
\hline & Job & 6 & 4.7 \\
\hline & Affordable real estates & 2 & 1.6 \\
\hline & Administrative and financial support & 5 & 3.9 \\
\hline & Living conditions such as education and culture & 5 & 3.9 \\
\hline & Total & 128 & 100.0 \\
\hline \multirow{11}{*}{ Current residence in Namhae county } & Gohyeon-myeon township & 5 & 3.5 \\
\hline & Nam-myeon township & 13 & 9.0 \\
\hline & Namhae-eup town & 34 & 23.6 \\
\hline & Mijo-myeon township & 13 & 9.0 \\
\hline & Samdong-myeon township & 21 & 14.6 \\
\hline & Sangju-myeon township & 24 & 16.7 \\
\hline & Seo-myeon township & 7 & 4.9 \\
\hline & Seolcheon-myeon township & 6 & 4.2 \\
\hline & Leedong-myeon township & 8 & 5.6 \\
\hline & Changseon-myeon township & 13 & 9.0 \\
\hline & Total & 144 & 100.0 \\
\hline
\end{tabular}

Note. Missing values within each variable were excluded for frequency analysis.

living conditions such as education and culture were at 3.25 and 3.24 respectively, which were above neutral, and friction with local people was neutral at 3.07. For the intent-to-persist, intent to move to another rural area and intent to go back to the city were below neutral at 2.87 and
2.99 respectively, and intent-to-recommend and intent-topublicize were above neutral at 3.40 and 3.46, respectively.

As previously mentioned, four variables related to intent-to-persist were transformed into a single variable (Equation 1 and Table 2). Only variables of satisfaction 
Table 5. Satisfaction and intent-to-persist of rural migrants settled in Namhae county

\begin{tabular}{|c|c|c|c|}
\hline \multicolumn{2}{|c|}{ Variable } & $\mathrm{N}$ & Mean \\
\hline \multicolumn{2}{|c|}{ Satisfaction with the settlement } & 142 & 3.67 \\
\hline \multirow{8}{*}{ Reason for satisfaction } & Hospitality of local people & 130 & 3.15 \\
\hline & Administrative services & 130 & 2.93 \\
\hline & Medical facilities and services & 130 & 2.70 \\
\hline & Living conditions such as education and culture & 130 & 2.98 \\
\hline & Beautiful natural environment & 130 & 3.99 \\
\hline & Healthy natural environment & 130 & 3.94 \\
\hline & Low living cost & 130 & 2.58 \\
\hline & Various income sources & 129 & 2.52 \\
\hline \multirow{5}{*}{ Reason for dissatisfaction } & Friction with local people & 130 & 3.07 \\
\hline & Administrative services & 130 & 3.25 \\
\hline & Medical facilities and services & 130 & 3.30 \\
\hline & Living conditions such as education and culture & 130 & 3.24 \\
\hline & Poor income sources & 129 & 3.32 \\
\hline \multirow{4}{*}{ Intent-to-persist } & Intent to move to another rural area & 137 & 2.87 \\
\hline & Intent to go back to the city & 136 & 2.99 \\
\hline & Intent to recommend & 139 & 3.40 \\
\hline & Intent to publicize & 138 & 3.46 \\
\hline
\end{tabular}

Note. Missing values within each variable were excluded for descriptive analysis.

Table 6. Correlation matrix of intent-to-persist and satisfaction of rural migrants settled in Namhae county

\begin{tabular}{ccccccccc}
\hline & IPE & SWS & SHL & SAS & SBN & SHN & DFL & DAS \\
\hline IPE & 1 & $.575^{* *}$ & $.362^{* *}$ & $.350^{* *}$ & $.225^{* *}$ & $.266^{* *}$ & $-.299^{* *}$ & $-.191^{*}$ \\
SWS & $.575^{* *}$ & 1 & $.363^{* *}$ & $.289^{* *}$ & .044 & $.195^{*}$ & $-.263^{* *}$ & -.110 \\
SHL & $.362^{* *}$ & $.363^{* *}$ & 1 & $.402^{* *}$ & $.276^{* *}$ & $.274^{* *}$ & $-.514^{* *}$ & -.148 \\
SAS & $.350^{* *}$ & $.289^{* *}$ & $.402^{* *}$ & 1 & .041 & .169 & .003 & $-.253^{* *}$ \\
SBN & $.225^{* *}$ & .044 & $.276^{* *}$ & .041 & 1 & $.572^{* *}$ & -.158 & .041 \\
SHN & $.266^{* *}$ & $.195^{*}$ & $.274^{* *}$ & .169 & $.572^{* *}$ & 1 & $-.224^{*}$ & -.068 \\
DFL & $-.299^{* *}$ & $-.263^{* *}$ & $-.514^{* *}$ & .003 & -.158 & $-.224^{*}$ & 1 & $.267^{* *}$ \\
DAS & $-.191^{*}$ & -.110 & -.148 & $-.253^{* *}$ & .041 & -.068 & $.267^{* *}$ & 1 \\
\hline
\end{tabular}

Note. IPE: intent-to-persist; SWS: satisfaction with settlement; SHL: satisfaction with hospitality of local people; SAS: satisfaction with administrative services; SBN: satisfaction with beautiful natural environment; SHN: satisfaction with healthy natural environment; DFL: dissatisfaction with friction with local people; DAS: dissatisfaction with administrative services.

${ }^{* *},{ }^{*}$ significant at $p<.01, p<.05$.

that were correlated with intent-to-persist were selected and presented in Table 6. Intent-to-persist (IPE) showed a highly significant positive correlation $(\mathrm{p}<.01)$ with satisfaction with settlement (SWS). This is consistent with Lee et al. (2004) and Whang (2006), and supports that higher satisfaction with settlement leads to higher intent-to-persist. Intent-to-persist showed a highly significant positive corre- lation $(\mathrm{p}<.01)$ with hospitality of local people (SHL), administrative services (SAS), beautiful natural environment (SBN), and healthy natural environment (SHN) in the reason for satisfaction. In the reason for dissatisfaction, it showed a highly significant or significant negative correlation $(\mathrm{p}<.01$ or $\mathrm{p}<.05)$ with friction with local people (DFL) and administrative services (DAS). Satisfaction with 
settlement showed a highly significant or significant positive correlation $(\mathrm{p}<.01$ or $\mathrm{p}<.05)$ with SHL, SAS, and SHN, while it showed a highly significant negative correlation $(\mathrm{p}<.01)$ with DFL. As a result, intent-to-persist and satisfaction with settlement were both affected by natural resources, relationships with local people, and administrative services (Choi et al., 2014; Whang, 2006), whereas they were not affected by medical facilities and services, living conditions such as education and culture, living costs, and income sources. This seems to be in line with the motives to migrate to rural areas and the main reasons for choosing Namhae county (Table 4), such as healthy lifestyle in rural areas, natural environment and interpersonal relationships.

\section{Recognition and intent-to-participate of URE business, including tourism}

Most rural migrants were in their 40s-50s, born and raised in urban areas, and have moved to Namhae county for leisure, health or natural environment of the county. They may have characteristics of both consumer and supplier in tourism businesses of the county. Thus, analyzing how rural migrants assess tourism in Namhae county will help find ways to revitalize URE business. It is important to analyze the attraction factors of tourist sites in order to understand the characteristics of the destinations that both attract and satisfy tourists (Medina-Munoz and MedinaMunoz, 2014). The major destinations recommended by rural migrants are categorized into 3 types as shown in Table 7. Terrestrial nature includes 4 destinations, marine nature includes 9 destinations, and culture/recreation includes 18 destinations. Namhae county is composed of islands and thus there are more marine nature resources listed than terrestrial nature resources, but more distinctive culture/recreation resources of the region are listed with a relatively higher frequency. This suggests that local culture is an important resource for developing community-based tourism (Giampiccoli and Kalis, 2012). 'German village' showed the highest frequency (65), followed by 'Geumsan mountain \& Boriam temple (59)', 'Daranginon in Gacheon village (47)', 'Sangju beach (27)', and 'Gardening art village (19)'. German village is a village in Mulgeon-ri village, Samdong-myeon township. In 2001, Namhae county invested over 3 billion KRW to prepare approximately 30,000 pyeong (24.5 acres) of land, which was parceled out for Koreans living in Germany, who had been sent to Germany in the 1960 s as nurses or mine workers, to resettle back in South Korea. The returnees imported materials from Germany and built traditional German-style houses, and currently this village serves as an important tourist spot that attracts many visitors. The fact that Namhae county designated German village as one of the most beautiful places of the county in the policy making process and

Table 7. Namhae county's major attractive destinations recommended by rural migrants

\begin{tabular}{|c|c|c|}
\hline Category & No. & Destination \\
\hline Terrestrial nature & 4 & $\begin{array}{l}\text { Geumsan mountain \& Boriam temple (59) }{ }^{*} \text {, Namhae cypress natural recreation forest (10), Mangunsan } \\
\text { mountain (4), Barae road (3) }\end{array}$ \\
\hline Marine nature & 10 & $\begin{array}{l}\text { Sanju beach (27), Mijo harbor (10), Mudflat experience (5), Coastal Roads (5), Jukbangnyeom (4), } \\
\text { Songjeong beach (3), Munhang fishing village (3), Sachon beach (2), Anchovy festival (2), Noryang } \\
\text { marintime scenic area (2) }\end{array}$ \\
\hline Culture \& recreation & 18 & $\begin{array}{l}\text { German village (65), Daranginon in Gacheon-ri village (47), Gardening art village 'house N garden' (19), } \\
\text { American village (8), Windbreak Forest of Mulgeon-ri village (7), General Lee, Sun-sin memorial park } \\
\text { (7), Sheep ranch (7), Hwabangsa Temple (5), Wind Trace Art Museum (5), Seomi garden (5), } \\
\text { Daeguksanseong Fortress (4), Dumo village (4), Namhae market (4), Butterfly Eco-Park (4), Gaengbeon } \\
\text { naru (3), Sangju Middle School } \\
\text { (2), Hyangchon-ri village (2), Farmfra village (2) }\end{array}$ \\
\hline
\end{tabular}

Note. ${ }^{*}$ Numbers in parentheses indicate the frequency of the respondents. Daranginon: It is the name given to the terraced rice fields created on a mountain slope to cultivate rice. Jukbangyeom: At Jijok Strait, the seawater flows at the relatively rapid speed of 13-15 km per hour; Anchovies are the most common catch in this part of the sea; Local fishermen use a traditional method of catching fish called jukbangnyeom, which consists in setting up a bamboo screen trap on a beach to catch fish at low tide. Windbreak Forest of Mulgeon-ri village: It is a forest about $1,500 \mathrm{~m}$ long and approximately $30 \mathrm{~m}$ wide along the coast; it was made by villagers about 300 years ago. 
solved the problems in the policy implementation process by financial support and reinforcement of self-government capabilities is a good example of rural tourism (Kim, 2010). Daranginon in Gacheon village is terraced rice paddy field with layers created on a mountain slope of Gacheon village in Nam-myeon township (Kweon and Lee, 2016). Gardening art village is adjacent to German village in Samdongmyeon township, and is a village with beautiful houses and gardens led and created by horticulture experts with the support of the Namhae county office. As a result, this suggests that terrestrial and marine natural resources themselves are also important, but cultural and recreational resources that are created based on such beautiful landscapes or healthy natural environments can be more frequently recognized as major destinations to visit. This is an important matter to consider in URE business that encompasses green tourism and rural tourism in the broad sense. Kim (2003) claimed that green tourism appears in the form of comprehensive implementation linked to local resources, and the implementation strategies are affected by four factors such as human resources, economic, cultural and natural resources, user behavior, and facilities.

The images rural migrants have about Namhae county were categorized into 4 types as shown in Table 8 . Natural environment features included 8 images, local places included 11 images, local products included 4 images, and local people included 1 image. 'Sea' showed the highest frequency (40), followed by 'Geumsan mountain \& Boriam temple (27)', 'Nature and landscape (19)', 'German village (16)', and 'Treasure island (11)'. The results indicate that
'Geumsan mountain \& Boriam temple (27)' and 'German village (16)' were not only the most important destinations to visit, but also the important images that represent Namhae county. Phillips et al. (2013) stated that destination image affects visitors' perception of value, satisfaction, intent-torevisit and intent-to-recommend, and a positive image is important in attracting re-visitors. As a result, the image of Namhae county showed to be linked to the dominant landscape features based on the islands and the county's distinctive places. Since the relationship with local people turned out to be a factor that affects satisfaction with settlement and intent-to-persist, the fact that unkindness of local people is selected as the image of Namhae county three times must be an important part to be considered for the revitalization of URE business including tourism.

In the assessment of tourism, rural migrants evaluated the tourism resources as excellent overall (Table 9): landscape of terrestrial nature and marine scenery were excellent at 4.04 and 4.01, respectively, and unique scenery of the villages and recreation area were close to excellent at 3.87 and 3.70 , respectively. Accessibility was rated below neutral: driving a car in Namhae county was at 2.69 and getting to Namhae county from the outside was at 2.92 . Facilities were rated at neutral: accommodation facilities were the highest at 3.17 among the items of facilities, and specialty/souvenir stores were the lowest at 2.80. Sanitation/ cleanliness and public relations/information were rated at neutral. The service of guides and the kindness of local people were at 3.07 and 2.95, respectively. Among the items of service and price, meals were the lowest at 2.68,

Table 8. Rural migrants' images of Namhae county

\begin{tabular}{|c|c|c|}
\hline Category & No. & Destination \\
\hline $\begin{array}{l}\text { Natural environmental } \\
\text { feature }\end{array}$ & 8 & $\begin{array}{l}\text { Sea (40), Nature and landscape (19), Treasure island (11), Clear air (8), Warm weather (4), Mountain } \\
\text { (4), Island (2), Fishing (2) }\end{array}$ \\
\hline Local place & 11 & $\begin{array}{l}\text { Geumsan mountain \& Boriam temple (27), German village (16), Daranginon in Gacheon village (6), } \\
\text { Sangju Beach (5), Recreation and tourism (5), Namhae bridge (5), Namhae cypress natural recreation } \\
\text { forest (4), Gardening art village 'house N garden' (2), Butterfly Eco-park (2), Barae road (2), } \\
\text { Mijo-myeon township (2) }\end{array}$ \\
\hline Local product & 4 & Garlic (7), Spinach (7), Citron (6), Anchovy (3) \\
\hline Local people & 1 & Unkindness ( 3$)$ \\
\hline
\end{tabular}

Note. ${ }^{*}$ Numbers in parentheses indicate the frequency of the respondents to the open-ended questions. They were able to respond up to nine destinations and up to three images. All of the destinations and the images were arranged in descending order of frequency. 
Table 9. Assessment of rural migrants on tourism resources, accessibility, facilities, sanitation and cleanliness, public relation and information, and service and price in Namhae county

\begin{tabular}{|c|c|c|c|}
\hline & Variable & $\mathrm{N}$ & Mean \\
\hline \multirow{4}{*}{ Tourism resources } & Landscape of terrestrial nature & 142 & 4.04 \\
\hline & Marine scenery & 143 & 4.01 \\
\hline & Unique scenery of the villages (Mulgun-ri village, etc.) & 143 & 3.87 \\
\hline & Recreation area (resorts \& hotels, golf clubs, beaches, etc.) & 142 & 3.70 \\
\hline \multirow{3}{*}{ Accessibility } & Getting to Namhae county from the outside & 143 & 2.92 \\
\hline & Driving a car in Namhae county & 143 & 2.69 \\
\hline & Parking lots and condition around tourist attractions & 143 & 3.02 \\
\hline \multirow{4}{*}{ Facilities } & Accommodation facilities & 143 & 3.17 \\
\hline & Convenience facilities such as kiosks, restaurants, public parking lots, etc. & 143 & 3.06 \\
\hline & Resting facilities such as rest areas, observatory, park, etc. & 143 & 3.03 \\
\hline & Specialty and/or souvenir stores & 143 & 2.80 \\
\hline \multirow{3}{*}{$\begin{array}{l}\text { Sanitation and } \\
\text { cleanliness }\end{array}$} & Toilets, drinking water fountains, etc. & 143 & 3.15 \\
\hline & Trash bin and waste management & 143 & 3.09 \\
\hline & Overall sanitation and cleanliness of Namhae county & 143 & 3.13 \\
\hline \multirow{2}{*}{$\begin{array}{l}\text { Public relation and } \\
\text { information }\end{array}$} & Prior to the visit, public relation/information of Namhae county through the Internet, etc. & 142 & 3.15 \\
\hline & Tourist information system, such as site maps, information facilities, etc. & 142 & 3.11 \\
\hline \multirow{2}{*}{ Hospitality } & Service and kindness of guides & 142 & 3.07 \\
\hline & kindness of local people & 141 & 2.95 \\
\hline \multirow{4}{*}{ service and price } & Accommodation & 142 & 3.17 \\
\hline & Meals & 141 & 2.68 \\
\hline & URE programs & 140 & 2.89 \\
\hline & Specialties and souvenirs & 141 & 2.69 \\
\hline
\end{tabular}

Note. Missing values within each variable were excluded for descriptive analysis.

followed by specialties and souvenirs and URE programs at 2.69 and 2.89 , respectively, and accommodations were above neutral at 3.17. Overall, rural migrants recognized that the tourism resources of Namhae county were excellent, but the quality of facilities, services, etc. were below average. Kweon and Lee (2016) mentioned in the study on Daranginon in Gacheon village that while coastal scenery, accessibility, and kindness were their strengths, convenience facilities, visitation costs, meal and beverage prices, purchase of local specialties, hands-on education programs, and various feasts and events were less satisfying. Schmidt et al. (2016) stated that collective action is essential for the development of sustainable rural tourism, in which individual or small businesses work together to improve their environments, form associations, syndicates and non-governmental organizations, and achieve common goals. As rural tourism-related businesses are interconnected and interdependent within the region, actions by individuals or small businesses to satisfy the tourists independently or exclusively may rather threaten the sustainability of rural tourism in the long run.

In order for UREs to revitalize the economy in rural areas, direct trade of agricultural products and various rural experience tours with local features are needed (Kang and Jeong, 2013). In the evaluation of URE programs operated in rural experience villages implementing UREs, all programs except for livestock experience were rated at 3.50 or higher (Table 10). Natural ecology experiences, visit to cultural sites, fishery experiences, experience of local festivals, special products, etc., and farming experience were particularly highly evaluated, which were linked to the local features of Namhae county. However, the overall quality of URE programs and the expertise in operation were rated the lowest at 3.34. This had a very significant correla- 
Table 10. Evaluation of urban-rural exchange programs in Namhae county

\begin{tabular}{|c|c|c|}
\hline Variable & $\mathrm{N}$ & Mean \\
\hline $\begin{array}{l}\text { Mudflat experience } \\
\text { (picking up short-necked clams, etc.) }\end{array}$ & 139 & 3.53 \\
\hline Farming experience (picking spinach, etc.) & 139 & 3.58 \\
\hline Livestock experience (Lamb ranch, etc.) & 140 & 3.47 \\
\hline $\begin{array}{l}\text { Wooden crafts experience } \\
\text { (making houses in German villages, etc.) }\end{array}$ & 140 & 3.51 \\
\hline $\begin{array}{l}\text { Natural ecology experience } \\
\text { (mudflat crab ecology experience, etc.) }\end{array}$ & 137 & 3.61 \\
\hline $\begin{array}{l}\text { Exploring historical sites } \\
\text { (Exploring fortress 'Daekuksanseong', etc.) }\end{array}$ & 140 & 3.53 \\
\hline Fishery experience (fishing experience, etc.) & 140 & 3.59 \\
\hline $\begin{array}{l}\text { Experience of local festivals, special products, etc. } \\
\text { (Anchovy festivals, etc.) }\end{array}$ & 139 & 3.58 \\
\hline $\begin{array}{l}\text { Visit to cultural sites } \\
\text { (German village, horticultural arts village, etc.) }\end{array}$ & 137 & 3.60 \\
\hline $\begin{array}{l}\text { Overall quality of URE programs and expertise in } \\
\text { operation }\end{array}$ & 138 & 3.34 \\
\hline
\end{tabular}

Note. Missing values within each variable were excluded for descriptive analysis.

tion $($ Pearson correlation $=.235$, significance $=.006)$ with the results of assessments that showed the quality of service and price of URE programs as less than neutral (Table 9), and indicated that rural migrants recognized the natural and cultural resources for URE businesses were excellent, but the development and operation of URE programs were below neutral. With regard to this, Kim (2001) stated that firstly an interpretation system must be established to efficiently operate experience programs. Kim (2001) also mentioned that an interpretation system must be established first to efficiently operate experience programs, and there is a need for well-organized legal and institutional strategies to develop experience programs capable of displaying the features of local resources, train/reeducate interpreters, and establish / supply information for interpretation.

In order to improve rural migrants' awareness and intent-to-participate in URE business, it is necessary to specifically analyze their recognition, behaviors, and intent-to-participate of URE business. Intent-to-participate was at 3.45 , which was between neutral and willing. Ma et al. (2015) said rural migrants had a desire to contribute to agricultural and regional development, but they seemed
Table 11. Intent-to-participate, awareness, necessity and assessment of rural migrants on URE business in Namhae county

\begin{tabular}{|c|c|c|}
\hline Variable & $\mathrm{N}$ & Mean \\
\hline Intent-to-participate & 143 & 3.45 \\
\hline Awareness & 143 & 3.20 \\
\hline Necessity & 143 & 3.69 \\
\hline $\begin{array}{l}\text { Assessment of the support from government or } \\
\text { local government }\end{array}$ & 142 & 3.51 \\
\hline
\end{tabular}

Note. Missing values within each variable were excluded for descriptive analysis.

to have a passive attitude toward URE business. Since URE is comprised of various activities to utilize rural spaces such as the natural environment, settlement spaces, and agricultural spaces, local residents must make voluntary efforts from multiple angles to revitalize their communities (Kang and Jeong, 2013), for which it is necessary to enhance their awareness of URE (Jang, 2013). Awareness was neutral at 3.20, and necessity was between neutral and necessary at 3.69, closer to necessary (Table 11). Assessment of the support from central/local government was between neutral and good at 3.51, closer to good. Jang (2013) mentioned that residents' awareness of URE must be enhanced by setting up programs to foster URE experts, reinforcing expert consulting, and benchmarking best practices. In the correlation analysis with intent-to-participate (IPS), awareness (AWB) did not show a correlation, whereas necessity (NEB) and assessment of the support from central/local government (ASG) showed a very significant positive correlation $(\mathrm{p}<.01)$ (Table 12). This indicates that intent-toparticipate is affected by the recognition of necessity and the support of central/local government.

Correlation analysis was conducted on variables related to intent-to-participate, satisfaction with settlement and intent-to-persist. Only the key variables with a significant correlation were selected and presented in Table 13. Intentto-participate (IPA) showed a very significant positive correlation $(\mathrm{p}<.01)$ with satisfaction with settlement (SWS). Among 4 variables related to intent-to-persist, intent-torecommend (IRE) and intent-to-publicize (IPU) showed a significant positive correlation $(\mathrm{p}<.05)$ with IPA. This indicates that it is necessary to consider the increase of both satisfaction with settlement and intent-to-persist in or- 
Table 12. Correlation matrix of intent-to-participate, awareness, necessity, and assessment of migrants on URE business in Namhae county

\begin{tabular}{ccccc}
\hline & IPU & AWB & NEB & ASG \\
\hline IPU & 1 & .158 & $.374^{* *}$ & $.239^{* *}$ \\
AWB & .158 & 1 & .160 & $.282^{* *}$ \\
NEB & $.374^{* *}$ & .160 & 1 & $.316^{* *}$ \\
ASG & $.239^{* *}$ & $.282^{* *}$ & $.316^{* *}$ & 1 \\
\hline
\end{tabular}

Note. IPS: intent-to-participation; AWB: awareness of urban-rural exchange business; NEB: necessity of urban-rural exchange business; ASG: assessment of the support of government or local government for urban-rural exchange business.

${ }^{* *},{ }^{*}$ significant at $p<.01, p<.05$.

Table 13. Correlation matrix of intent-to-participate, awareness, necessity, and assessment of migrants on URE business in Namhae county

\begin{tabular}{ccccc}
\hline & IPA & SWS & IRE & IPU \\
\hline IPA & 1 & $.271^{* *}$ & $.208^{*}$ & $.191^{*}$ \\
SWS & $.271^{* *}$ & 1 & $.493^{* *}$ & $.485^{* *}$ \\
IRE & $.208^{*}$ & $.493^{* *}$ & 1 & $.752^{* *}$ \\
IPU & $.191^{*}$ & $.485^{* *}$ & $.752^{* *}$ & 1 \\
\hline
\end{tabular}

Note. IPA: intent-to-participation; SWS: satisfaction with settlement; IRE: intent-to-recommend; IPU: intent-to-publicize.

${ }^{* *},{ }^{*}$ significant at $p<.01, p<.05$.

der to enhance intent-to-participate.

In the correlation analysis of intent-to-participate and variables related to assessment of tourism resources, facilities, services, etc., variables correlated with intent-to-participate were 4 variables included in tourism resources, driving a car in Namhae county, and the service and price of meals (Table 14). Assessment of the landscape of terrestrial nature (ALA) and recreation area (ARE) showed a very significant positive correlation $(\mathrm{p}<.01)$ with IPA, while the rest showed a significant positive correlation $(\mathrm{p}<.05)$. Among the variables, the effective ways to enhance the intent-to-participate may be improving the resort area, the accessibility such as shuttle bus service, and the service and price of restaurants to satisfy visitors. With regard to this, as mentioned by Yu et al. (2013), it is necessary to secure unique and reasonably-priced accommodations, improve the service of restaurants, and present local cuisine. Indigenous food, artworks and handicrafts are attractions that show the local culture, and especially the unique local
Table 14. Correlation matrix of intent-to-participate and different variables of tourism resources, facilities, and services in Namhae county

\begin{tabular}{cccccccc}
\hline & IPA & ALA & AMA & AUN & ARE & ADR & AME \\
\hline IPA & 1 & $.218^{* *}$ & $.199^{*}$ & $.205^{*}$ & $.293^{* *}$ & $.164^{*}$ & $.166^{*}$ \\
ALA & $.218^{* *}$ & 1 & $.649^{* *}$ & $.619^{* *}$ & $.254^{* *}$ & .041 & .006 \\
AMA & $.199^{*}$ & $.649^{* *}$ & 1 & $.395^{* *}$ & $.195^{*}$ & .029 & .015 \\
AUN & $.205^{*}$ & $.619^{* *}$ & $.395^{* *}$ & 1 & $.396^{* *}$ & .119 & .155 \\
ARE & $.293^{* *}$ & $.254^{* *}$ & $.195^{*}$ & $.396^{* *}$ & 1 & .144 & $.255^{* *}$ \\
ADR & $.164^{*}$ & .041 & .029 & .119 & .144 & 1 & $.285^{* *}$ \\
AME & $.166^{*}$ & .006 & .015 & .155 & $.255^{* *}$ & $.285^{* *}$ & 1 \\
\hline
\end{tabular}

Note. IPA: intent-to-participation; ALA: assessment of the landscape of terrestrial nature; AMA: assessment of the marine scenery; AUN: assessment of the unique scenery of the villages; ARE: assessment of the recreation area; ADR: assessment of driving a car in Namhae county; AME: assessment of the service and price of meals.

${ }^{* *, *}$ significant at $\mathrm{p}<.01, \mathrm{p}<.05$.

cuisine has the potential to provide visitors with the joy of traveling away from everyday routines and facilitate a number of community benefits (Bessiere and Tibere, 2013; Giampiccoli and Kalis, 2012).

Information source and experience of participation were analyzed to seek for ways to enhance rural migrants' awareness and intent-to-participate in URE business. As for the information source in URE exchange projects, people around (family / friends / colleagues, etc.) were the highest at $33.9 \%$, followed by the internet at $20.5 \%$ (Table 15 ). This indicates that the relationship with the local people is important for rural migrants, and at the same time, the hospitality of the local people is required. As for experience of participation, currently participating was very low at $9.1 \%$, and no experience (none) was very high at $61.5 \%$. As a result, $38.5 \%$ of rural migrants had experience of participation. In the question of intent-to-participate in URE business, 55.3\% responded willing or very willing, and the average value was 3.45 in 5-point of Likert scale (Table 11). Considering these results, the Namhae county office must come up with ways to increase opportunities for experience of participation. Park and Kim (2010) stated that rural tourism must be connected as a collective action of the entire village, so it is necessary to develop experience products and routes linked to local features in which all members can participate. Through the medium of URE, 
Table 15. Information source and experience of participation in URE businesses

\begin{tabular}{clrr}
\hline & Variable & Frequency & Percent (\%) \\
\hline & Internet (Homepage, etc.) & 23 & 20.5 \\
& Social media (Facebook, Twitter, etc.) & 14 & 12.5 \\
& TV/radio & 11 & 9.8 \\
& Newspaper/magazine & 13 & 11.6 \\
Information source & Banner/advertising tower & 1 & 0.9 \\
& People around (family/friend/colleague, etc.) & 38 & 33.9 \\
& Municipal office & 10 & 8.9 \\
& Others & 2 & 1.8 \\
& Total & 112 & 100.0 \\
& Currently participating & 13 & 9.1 \\
& Participated in the past & 42 & 29.4 \\
& None & 88 & 13.5 \\
& Total & 143 & 100.0 \\
\hline
\end{tabular}

Note. Missing values within each variable were excluded for frequency analysis.

new information is shared, and in the process of sharing culture, the local people can develop a positive perception of the region, which can be the driving force to voluntarily revitalize the region (Kang and Jeong, 2013).

The goals of URE business are to build infrastructures in rural areas, improve cultural life, revitalize the region, create jobs, and generate income (Bessiere and Tibere, 2013; Chancellor et al., 2011; Jang, 2013; Ma et al., 2015). Importance-performance analysis (IPA) was conducted on the expected effects of rural migrants and the benefits achieved so far for these goals (Fig. 1). A total of three variables were located in quadrant 1 , where both importance and performance were high: 'getting more income from increased visitors (2)', 'enhancing cultural life (3)', and 'local revitalization (4)'. A total of two variables, 'infrastructure construction (1)' and 'job creation (5)', were located in quadrant 3 , where both importance and performance are low. According to the results of Martilla and James (1977), 'getting more income from increased visitors (2)', 'enhancing cultural life (3)', and 'local revitalization (4)' were included to the area of 'keep up the good work' (quadrant 1), and thus the performance needs to be kept at the same level. On the other hand, 'infrastructure construction (1)' and 'job creation (5)' can be interpreted as 'low priority'. This implies that rural migrants perceive the region is being continuously revitalized, are demanding the

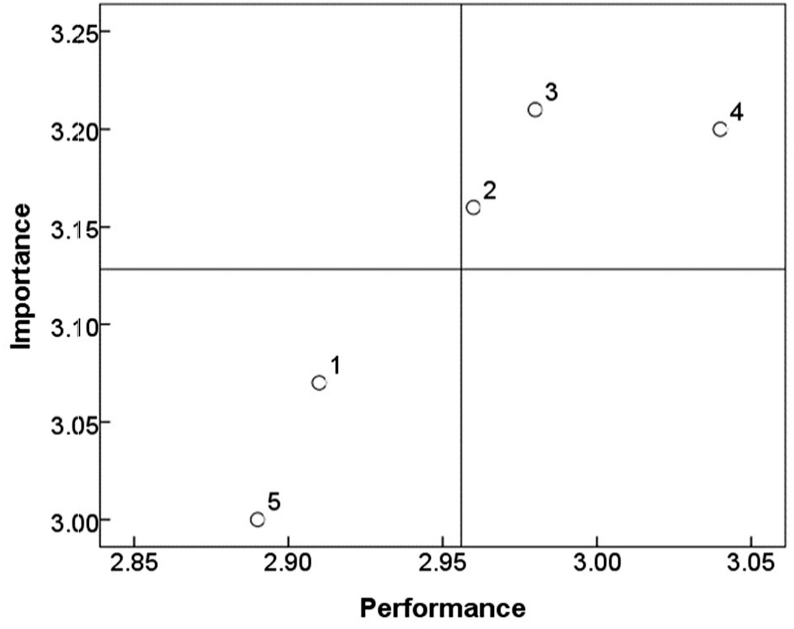

Fig. 1. IPA of migrants on URE in Namhae county : $1=$ infrastructure construction, 2 = getting more income from increased visitors, $3=$ Enhancing cultural life, $4=$ local revitalization, 5 = job creation.

enhancement of cultural life, and are expecting more income generation from increased visitors rather than job creation.

In order to revitalize URE business, the missions that the Namhae county office must focus on were establishing internal and external public relation system with the highest score (3.87), followed by establishing the support system of the central/local government (3.75), and training and supporting local leaders (3.73) (Table 16). Training experts on URE and improving the expertise of the department 
Table 16. Missions of Namhae county office to focus on to revitalize URE business

\begin{tabular}{lllc}
\hline \multicolumn{1}{c}{ Variable } & $\mathrm{N}$ & Mean & Standard Error \\
\hline Improve the expertise of the department & 142 & $3.51 \mathrm{~b}^{\mathrm{z}}$ & 0.07 \\
Train experts on urban-rural exchanges & 142 & $3.67 \mathrm{ab}$ & 0.08 \\
Train and Support local leaders & 142 & $3.73 \mathrm{ab}$ & 0.07 \\
Establish support system of government or local government & 142 & $3.75 \mathrm{ab}$ & 0.08 \\
Establish internal and external public relation system & 142 & $3.87 \mathrm{a}$ & 0.07 \\
\hline
\end{tabular}

${ }^{\mathrm{z}}$ Means followed by different letters within columns are significantly different at $p=.05$ by Tukey's range test.

Note. Missing values within each variable were excluded for descriptive analysis.

were both higher than 3.50. In the assessment of the importance or priority of the missions, there was a statistically significant difference between establishing internal and external public relation system and improving the expertise of the department $(p<.05)$. The results suggest rural migrants recognized that the support of the Namhae county office is needed to revitalize URE business, and that the Namhae county office must focus more on establishing internal/external public relation system, establishing support system of the central/local government, and training/supporting local leaders than improving the expertise of the department.

\section{Conclusion}

URE business aims to revitalize rural areas and a large portion of it is linked to tourism, mainly green tourism and rural tourism. As a major human resource for revitalizing URE business, it is necessary to enhance the rural migrants' recognition and intent-to-participate. With focus on Namhae county, rich in natural and cultural resources, this study analyzed the rural migrants' recognition and intent-to-participate of URE business and suggested ways for enhancement.

Most were in their 40s and 50s and had no experience of living in rural areas. Their motives to migrate to rural areas were to enjoy leisure life after retirement, increased tiredness of city life, health reasons, etc. In choosing the place for migration, natural environment and interpersonal relationships were more important than economic factors. Satisfaction with settlement level was close to satisfied, and both intent-to-recommend and intent-to-publicize were between neutral and willing. Intent-to-persist and satisfaction with settlement were affected by natural resources, relationships with local people and administrative services, but were not affected by living costs or income sources. The important attractive destinations recommended by the rural migrants were more in the category of culture \& recreation resources than that of natural resources. Their images of Namhae county were linked to the landscape features based on the islands and the county's distinctive places. They recognized that tourism resources were excellent, but the facilities and services to support them were below neutral. Similarly, it was recognized that while natural and cultural resources of URE programs were excellent, the operation of the programs was below neutral. Intent-to-participate was between neutral and willing, affected by the recognition of necessity and support of the central/local government, as well as by satisfaction with settlement, intent to recommend and publicize, tourism resources, driving a car in Namhae county, and the service and price of meals. Major information sources were people around and the internet. There were fewer participation opportunities compared to the relatively high level of intent-to-participate. They recognized the region was getting vitalized, demanded the enhancement of cultural life, and expected to earn more income from increased visitors rather than job creation. The missions on which the Namhae county office must focus were establishing internal/external public relation systems, establishing support systems of the central/local government, and training/supporting local leaders rather than improving the expertise of the department.

In order to enhance rural migrants' recognition and intent-to-participate of URE business, it is necessary to increase satisfaction with settlement and intent-to-persist by 
improving relationships between migrants and local people, and administrative services. Next, it is necessary to expand the interpersonal exchanges between migrants and local people, to expand the major information sources of URE business, to establish internal/external public relation systems, to train and support local leaders, to reinforce transportation within the county, to improve the service and price of meals, to develop rural tourism and URE programs, and to improve the operation of URE programs. In this regard, additional research needs to be conducted in the future.

\section{References}

Bessiere, J. and L. Tibere. 2013. Traditional food and tourism: French tourist experience and food heritage in rural spaces. J. Sci. Food Agric. 93(14):3420-3425. http://doi.org/10.1002/jsfa.6284

Chancellar, C., C.P.S. Yu, and S.T. Cole. 2011. Exploring quality of life perceptions in rural midwestern (USA) communities: an application of the core-periphery concept in a tourism development context. Int. J. Tour. Res. 13(5):496-507. https://doi.org/10.1002/jtr.823

Choi, Y.J., J.I. Hwang, and H.Y. Shin. 2014. An analysis of satisfaction in the rural settlement of returning farmers. Korean J. community Living Sci. 25(3): 321338. https://doi.org/10.7856/kjcls.2014.25.3.321

Giampiccoli, A. and J. H. Kalis. 2012. Tourism, food, and culture: community-based tourism, local food, and community development in Mpondoland. Cult. Agric. Food Environ. 34(2):101-123. https://doi.org/10.1111/j.21539561.2012.01071.x

Han, S.Y. 2005. An analysis of urban residents' preference on urban-rural interchange. J. Korean Inst. For. Recreat. 9(2):29-35.

Jang, I.B. 2013. Recognition survey and policy implications to promote urban and rural exchange among local governments. Korean J. Pol. Anal. Eval. 23(3):177-200.

Kang, J.H. and S.H. Jeong. 2013. A study on sustainable measures of 1 company - 1village campaign for the activation of urban-rural exchange: focusing on the Gongju city. J. Rural Tour. 20(2):121-135.

Kim, B.S. 2003. A study of Classification on green tourism practices. J. Korean Inst. For. Recreat. 7(2):43-51.
Kim, I. and K.Y. Huh. 2019. Assessment of residents' understanding and demands on gardens in Gyeongnam region, Korea. J. People Plants Environ. 22(2):167-180. http://doi.org/10.11628/ksppe.2019.22.2.167

Kim, J.M. and N.R. Jeong. 2006. The study of promotional strategy of traditional culture tourism - in Sunchang pepper paste folk village. J. Korean Inst. For. Recreat. 10(3):21-29.

Kim, J.Y. 2010. Policy process and success factor for green growth policy in local government level: focused on Namhae-gun's. Korean J. Local Gov. Stud. 14(2): 83-103.

Kim, S.Y. 2001. A study on effective management of green tourism program in Japan. J. Korean Inst. For. Recreat. 5(2):51-60.

Kweon, D.G. and J. Lee. 2016. Importance-satisfaction analysis of selection attributes by coastal landscape users: a case of Darengyi-village, Namhae. J. Isl. Cult. 47:145-168.

Lee, H.C., H.B. Park, and W.I. Choung. 2004. An analysis on the factors to affect the settlement consciousness of inhabitants. Korea Assoc. Policy Stud. 13(3):147-169.

Lee, Y.J., K.Y. Huh, I. Kim, and H.D. Bui. 2019. Assessment of visitors' satisfaction and intention to revisit of Bukcheon Iceland poppy festival in Hadong county, South Korea. J. People Plants Environ. 22(6): 629-639. http://doi.org/10.11628/ksppe.2019.22.6.629

Ma, S.J., D.S. Park, S.H. Park, Y.W. Choi, K.C. Nam, S.H. Nam, and Y.J. Choi. 2015. A trend analysis of urban-rural migrants background, economic activity, and community participation. J. Agr. Edu. Hum. Resour. Dev. 47(2):1-21.

Martilla, J.A. and J.C. James. 1977. Importance-performance analysis. J. Mark. 41(1):77-79. http://doi.org/10. $2307 / 1250495$

Medina-Munoz, D.R. and R.D. Medina-Munoz. 2014. The attractiveness of wellness destinations: an importanceperformance-satisfaction approach. Int. J. Tour. Res. 16(6):521-533. https://doi.org/10.1002/jtr.1944

Park, Y.J. and T.H. Kim. 2010. A study on revitalization of rural sightseeing village through participation of residents - with focus on Iksan city. J. Korean Inst. For. Recreat. 14(3):1-9.

Phillips, W.M.J., K. Wolfe, N. Hodur, and F.L. Leistritz. 2013. Tourist word of mouth and revisit intentions to 
rural tourism destinations: a case of North Dakota, USA. Int. J. Tour. Res. 15(1):93-104. https://doi.org/10.1002/ jtr.879

Saxena, G. 2014. Rural tourism partnerships and actor mobility. Int. J. Tour. Res. 16(5):488-495. http://doi.org/10.1002/jtr.1942

Schmidt, C.M., I.D. Cielo, K.R. Wenningkamp and M, Tomio. 2016. Collective actions in sustainable rural tourism: a case study of the western region of Parana. Syst. Res. 33(2):249-258. http://doi.org/10.1002/sres.2380

Whang, H.D. 2006. A study on the development strategies of rural settlement regions in Gyeongnam province. J. Agric. Life Sci. 40(3):1-25.

Yu, C.J., C.S. Kang, and D.H. Jang. 2013. Intention analysis of Sunchang area tourists for local tourism. Korean J. Agric. Sci. 40(3):261-269. 